\title{
Stereotactic direct-coiling of aneurysms-a feasibility study
}

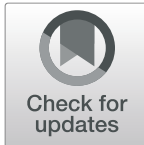

Arun Angelo Patil ${ }^{1 *}$, Deepak Kumar Pandey ${ }^{2}$, Sidhartha Kumar ${ }^{1}$, Ashis Chand ${ }^{3}$ and Megha Jacob ${ }^{1}$

\begin{abstract}
Aim of the study: Endovascular coiling has gained worldwide acceptance in the management of intracranial aneurysms. However, not all aneurysms can be coiled. Direct aneurysm puncture with aneurysm thrombosis has been performed, using coils for extracranial aneurysms and iron filings for intracranial aneurysms. Therefore, the feasibility of stereotactic aneurysm coiling with direct aneurysm puncture using Nester-coils was studied in an in vitro model.

Methods and findings: Twenty-eight aneurysms measuring 9-21 mm in diameters (median $14 \mathrm{~mm}$ ) were made using $0.1 \mathrm{~mm}$ vinyl film that was connected to a monometer with $73 \mathrm{~cm}$ of water column. Twenty-three aneurysms were coiled through direct puncture of the aneurysms using a stereotactic frame. Five were coiled using a handheld probe carrier.

Statistical analysis of the data was conducted by data analysis feature of Microsoft Excel.

Findings: The study showed that needle puncture of the aneurysm and coiling of the aneurysm through the needle can be done with ease and without any significant fluid leak from the puncture site. It also shows that the coil will stay within the aneurysm without entering the neck. The study also shows that this method can be done using free-hand technique. Furthermore, it shows that the probe holder for the needle can also be used as an aneurysm stabilizer and as a tamponade.
\end{abstract}

Keywords: Direct-coiling, Stereotactic surgery, Cerebral aneurysms, Subarachnoid hemorrhage, Neurosurgery

\section{Introduction}

\section{Background}

Aneurysmal subarachnoid hemorrhage (SAH) is one of the most dangerous neurological condition with incidence of 7.9 per 100,000 population [1]. The mortality rate for this condition is $45 \%$, and in those who survive, there is a high rate of severe morbidity. Thirty percent of patients will rebleed within the first month. This further worsens the prognosis. Therefore, early obliteration of the aneurysm is needed.

There are two principal modalities to treat this condition. One method is to clip the neck of the aneurysm.

\footnotetext{
* Correspondence: aapati@@cox.net

Podium presentation at the Congress of neurological Surgeons San

Francisco, CA, USA, October 2019

'Department of Surgery, Creighton University School of Medicine, 7710

Mercy Road, Suite 501, Omaha, NE 68124, USA

Full list of author information is available at the end of the article
}

This requires brain retraction, which can be dangerous if the patient also has brain swelling and/or vasospasm. The other method is endovascular coiling of the aneurysmal sac. The complications of this procedure include perforation of the aneurysm, incomplete occlusion of the aneurysm, and ischemic complication [2]. A major advantage of the endovascular method is that it is a percutaneous procedure and that can be safely performed in the presence of brain swelling. In a randomized trial in patients with good clinical status that had aneurysmal rupture, coiling had better results than clipping [3]. Endovascular obliteration, therefore, is a preferred method in many centers.

\section{Aim of the study}

Though the current methods are good and have worldwide acceptance, they have their limitations. Not all 
aneurysms are suitable for coiling, because of the vascular anatomy or intra-vascular pathology. Vasospasm and brain swelling can prevent early clipping, or clipping may not be possible due to severe scarring around the aneurysm or due to complex perianeurysmal vasculature. In addition, in some hospitals, an endovascular facility may not be available. Therefore, the aim of the study is to determine if it is feasible to directly coil the aneurysm via direct puncture using stereotactic or free-hand technique.

\section{Existing literature}

Direct aneurysm puncture with embolization of visceral and extracranial aneurysms has been reported by Dik et al. [4] in 10 cases. Nine of them were pseudoaneurysms and 1 was real. Glue (6 cases), coils (3 cases), and thrombin (1 case) were used as embolic agents. The authors concluded that it was as efficacious as the endovascular method. Berkman et al. [5] performed coiling of a giant internal carotid artery aneurysm in the neck via direct puncture. Smith and Alksne [6] reported stereotactic aneurysm thrombosis with carbonyl iron powder suspended in methyl methacrylate polymer in 15 patients via direct puncture.

Patil et al. in 1984 [7] reported direct coiling of experimentally created external carotid artery aneurysms in 10 dogs using polypropylene coil and methyl methacrylate polymer, with complete thrombosis of the aneurysm without any complication. In 1986 [8], they created abdominal aorta aneurysms using vein grafts in 75 rats. These aneurysms were then thrombosed using a 22gauge RF needle. None of the aneurysms bled from the needle puncture.

A necessity for this study is that though there are few reports of coiling visceral and extracranial aneurysm via direct aneurysm puncture, there is none for intracranial aneurysm. Unlike visceral and extracranial aneurysms, intracranial aneurysms are smaller and have thin and fragile walls. Therefore, a feasibility study was required to study this approach using experimental aneurysms with an extremely thin wall.

\section{Methods/experimental}

\section{The aim and design setting}

The aim of the design was to create aneurysms of extremely thin material and maintain pressure within it that would mimic intracranial intra-aneurysmal pressure. To reduce fluid leak, the smallest possible gauge of needle that is capable of transmitting coils was used. Nester coils (Cook Medical, Bloomington Indian, USA) 5 and $10 \mathrm{~cm}$ in expanded length and coil diameter of $5 \mathrm{~mm}$ were used for the study.

\section{Materials and setting}

Twenty-eight aneurysms measuring $9-21 \mathrm{~mm}$ in diameters (median $14 \mathrm{~mm}$ ) and a neck of $3.6 \mathrm{~mm}$ (inner diameter) were made using $0.1 \mathrm{~mm}$ vinyl film. The aneurysm was connected to a monometer with $73 \mathrm{~cm}$ of water column. Twenty-three aneurysms were coiled using a stereotactic frame. Five were treated using free-hand technique.

\section{Method}

A stereotactic frame was used to target a point on the dome of the aneurysm. The probe-holder had an outer diameter of $3.9 \mathrm{~mm}$ and an inner diameter of $0.819 \mathrm{~mm}$. A stopper was used to limit the exposed needle tip to 3 $\mathrm{mm}$ distal to the probe holder. The probe holder was lowered until it touched the dome of the aneurysm. A 15-cm, 21-gauge, trocar-needle was inserted through the probe holder to place its tip into the aneurysm (Fig. 1). Upon entering the aneurysm, a pop was felt, and fluid egressed from the hub of the needle. One to 4 coils (5 $\mathrm{mm}$ in diameter and $5 \mathrm{~cm}$ in length) were pushed into the aneurysm by means of a stylet (Fig. 2). In two aneurysms, coils with a coil diameter of $5 \mathrm{~mm}$ and length of $10 \mathrm{~cm}$ were used. In 15 procedures, the coils were preloaded into needle used for aneurysm puncture (15 procedures) prior to puncturing the aneurysms and in 13 procedures the coils were loaded into the needle used

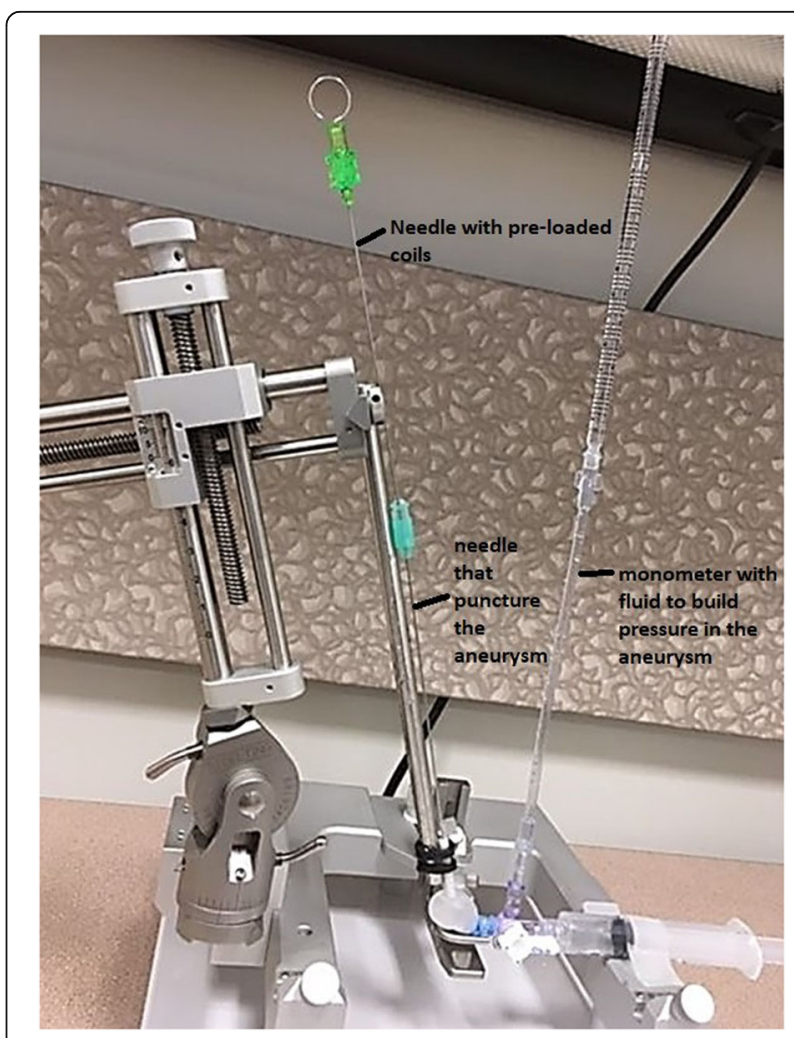

Fig. 1 Shows in vitro set-up of the experiment set 


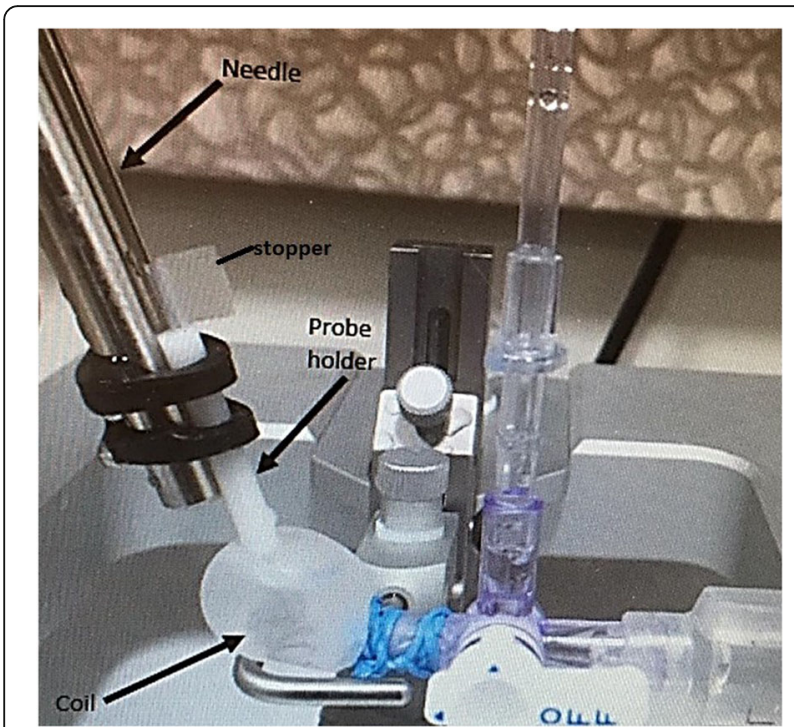

Fig. 2 Shows the coil in the aneurysm

for puncturing the aneurysm after the aneurysm was punctured using another needle that had pre-loaded coils. In both situations, if additional coil were needed for insertion, they were put into the puncturing needle while it was still in the aneurysm using another needle with pre-loaded coils.

In 5 studies, aneurysms were punctured using freehand technique. First, the probe holder was placed on the surface of the dome of the aneurysm (Fig. 3). Next, the needle tip was inserted into the aneurysms. Next, the coli(s) coils were pushed into them, using the technique described above.

No attempt was made to totally pack the sac, and at the conclusion of the experiments, fluid from the aneurysm was sucked out using a $10-\mathrm{ml}$ syringe. The aneurysm was then cut opened to see if any of the coils entered the neck.

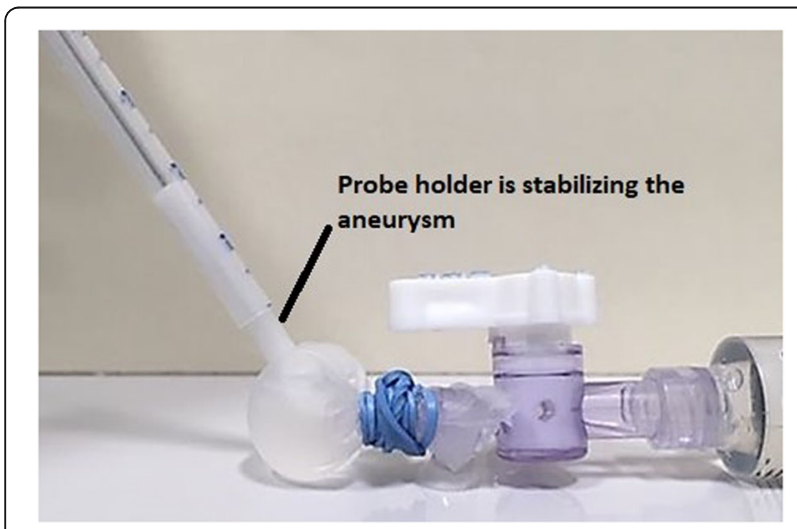

Fig. 3 A free-hand aneurysm coiling procedure. The probe holder has stabilized the aneurysm
Fluid leak at the puncture site was recorded in terms of the number of drops. One drop of fluid was taken to be $61.60 \mu \mathrm{l}$.

\section{Statistical analysis}

Statistical analysis was done using $t$ test two-sample assuming unequal variance was done using the data analysis feature of Microsoft Excel.

\section{Results}

Direct aneurysmal coiling was successful in all cases (Table 1). It was easy to push the coil through the needle into the aneurysm using the stylet. It was also easy to load additional coils into the needle using the loading needle (that was pre-loaded with coils). The probeholder acted as a tamponade and minimized fluid leak from the puncture site.

The average fluid loss at the puncture site was $40.17 \mu \mathrm{l}$, which is significantly less than the average volume of aneurysm $2052.71 \mu \mathrm{l}(\mathrm{t} 22=-7.688, p$ value $=$ 0.000 ). The average diameter of aneurysm treated with 1 coil was $15.024 \mathrm{~mm}$, and those treated with multiple coils was $15.733 \mathrm{~mm}$. There was not statistically different $(\mathrm{t} 11=-0.540, p$ value $=0.300)$ in size. However, the average fluid loss at the puncture in those treated with multiple coils was $0 \mu \mathrm{l}$, compared to those with singlecoil implant $55.353 \mu \mathrm{l}(\mathrm{t} 16=3.453, p$ value $=0.002)$. None of the coils entered the neck

\section{Discussion}

In this study, to mimic the pressure within a true aneurysm, the pressure within the aneurysm was raised to $73 \mathrm{~cm}$ of water $(54 \mathrm{mmHg})$ using a monometer that was connected to the neck of the aneurysm. It is hard to mimic the wall of an aneurysmal wall because no two aneurysms have the same thickness or elasticity. The authors, therefore, chose $0.1 \mathrm{~mm}$ thickness vinyl membrane to form the aneurysm. A trocar-tipped needle was used to penetrate the aneurysm because it needs the least force for penetration [9]. The needle was $21 \mathrm{G}$ because the available coils can easily pass through it

Nester push-able coils were used because they were MRI compatible. They had coil length from 3 to $20 \mathrm{~cm}$ and coil diameters from 2 to $20 \mathrm{~mm}$. Furthermore, they can be easily pushed through a 21 -gauge needle. The available sizes make it possible to coil aneurysms with wide neck and large domes. Since the neck of the experimental aneurysms was $3.5 \mathrm{~mm}$ in this study, we used a coil diameter of $5 \mathrm{~mm}$. Although the coils were inserted through the dome, none of the coils entered the neck.

There is always a concern if this in vitro study will successfully translate into in vivo clinical experience. Since aneurysms do rupture spontaneously, it is possible that even a small pressure on it can cause it to rupture. 
Table 1 Direct aneurysmal coiling

\begin{tabular}{|c|c|c|c|c|c|}
\hline $\begin{array}{c}\text { Aneurysm } \\
\text { number }\end{array}$ & $\begin{array}{c}\text { Diameter of } \\
\text { Aneurysm } \\
(\mathbf{m m})\end{array}$ & $\begin{array}{c}\text { Volume of } \\
\text { Aneurysm }(\boldsymbol{\mu} \mathbf{l})\end{array}$ & $\begin{array}{c}\text { Fluid Loss Upon } \\
\text { Puncture Of } \\
\text { The Aneurysm } \\
(\boldsymbol{\mu})\end{array}$ & $\begin{array}{c}\text { Ratio Of Fluid } \\
\text { Loss To The } \\
\text { Aneurysm } \\
\text { Volume(\%) }\end{array}$ & $\begin{array}{c}\text { Number Of } \\
\text { Coils Inserted }\end{array}$ \\
\hline 1 & 11.70 & 838 & 0 & $0 \%$ & 1 \\
\hline 2 & 13.70 & 1346 & 0 & $0 \%$ & 1 \\
\hline 3 & 14.40 & 1563 & 0 & $0 \%$ & 1 \\
\hline 4 & 12.00 & 904 & 0 & $0 \%$ & 2 \\
\hline 5 & 22.00 & 5572 & 0 & $0 \%$ & 1 \\
\hline 6 & 17.90 & 3001 & 0 & $0 \%$ & 1 \\
\hline 7 & 13.10 & 1177 & 123 & $10 \%$ & 1 \\
\hline 8 & 14.50 & 1595 & 62 & $4 \%$ & 1 \\
\hline 9 & 11.30 & 755 & 0 & $0 \%$ & 1 \\
\hline 10 & 13.20 & 1204 & 0 & $0 \%$ & 1 \\
\hline 11 & 14.40 & 1563 & 185 & $12 \%$ & 1 \\
\hline 12 & 16.00 & 2144 & 62 & $3 \%$ & 1 \\
\hline 13 & 16.30 & 2266 & 0 & $0 \%$ & 1 \\
\hline 14 & 20.80 & 4709 & 0 & $0 \%$ & 1 \\
\hline 15 & 16.40 & 2308 & 123 & $5 \%$ & 1 \\
\hline 16 & 9.50 & 449 & 123 & $27 \%$ & 1 \\
\hline 17 & 16.20 & 2225 & 123 & $6 \%$ & 1 \\
\hline 18 & 16.20 & 2225 & 0 & $0 \%$ & 3 \\
\hline 19 & 14.00 & 1436 & 123 & $9 \%$ & 1 \\
\hline 20 & 18.00 & 3052 & 0 & $0 \%$ & 2 \\
\hline 21 & 19.10 & 3647 & 0 & $0 \%$ & 2 \\
\hline 22 & 14.10 & 1467 & 0 & $0 \%$ & 4 \\
\hline 23 & 15.00 & 1766 & 0 & $0 \%$ & 4 \\
\hline & & & & & \\
\hline
\end{tabular}

Therefore, the biggest concern about stereotactic aneurysm coiling, is, aneurysm rupture during needle puncture. However, the present study shows that leaks at the puncture site is minimal and none when multiple coils are implanted. Furthermore, it is common practice to needle aneurysm after it is clipped to determine if the clipping is complete. No adverse result has been reported from this method.

In the series published by Smith et al. [6], stereotactic aneurysm punctures were done to inject thrombogenic material into the aneurysms. There is no incidence of aneurysm rupture in this series. In addition, in a previous study by Patil et al. [8], 75 experimentally created aneurysms on rats' abdominal aorta were punctured with RF-probe to thrombose the aneurysm. None of the aneurysms ruptured during the puncture. The abovementioned reports, therefore, suggest that the risk of rupture from aneurysmal puncture is small. This risk is further reduced by the probe-holder which stabilized the aneurysm and acts as a tamponade. In addition, the stereotactic frame will give a rigid hold to the probe.

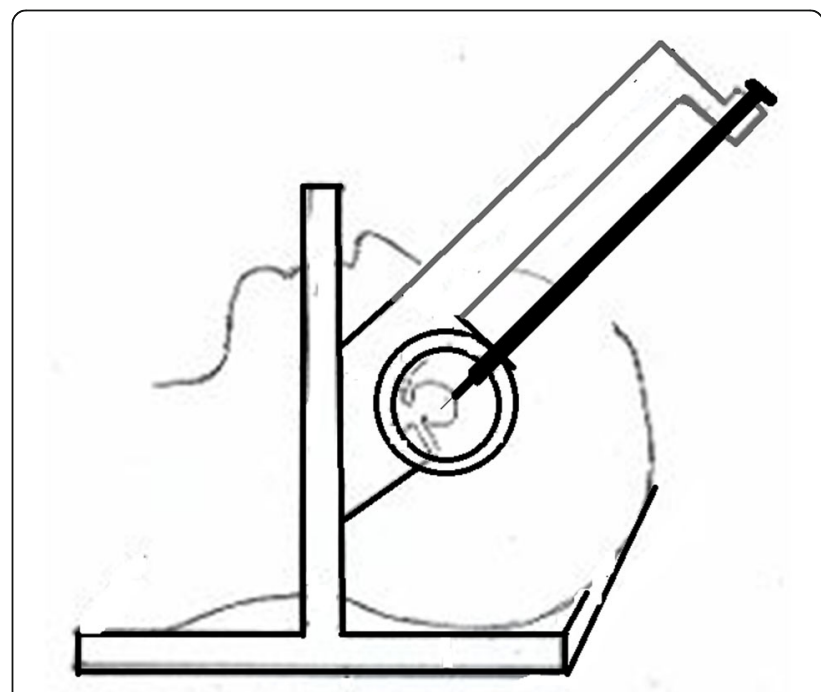

Fig. 4 Clinical set-up for stereotactic coiling 
This would enable a stable end-on entry of the needle into the aneurysm (Fig. 4). Furthermore, the anatomy of perianeurysmal vasculature can be extremely complex. Therefore, there is always a risk of injury to the perforating vessels around aneurysms. Proper planning of the trajectory, using a CT angiogram, would reduce this risk. In addition, a rigid endoscope can be stereotactically inserted to a point just above the dome of the aneurysm prior to the insertion of the needle, to visualize the surface of the aneurysm.

Stereotactic approach offers several advantages. Good trajectory planning allows the surgeon to choose a path that is safe. Similarly, the safest possible entry point into the dome of the aneurysm can be chosen. The method does not need brain retraction and can be performed even if there is severe arterial spasm.

Direct aneurysm coiling can also be done through open craniotomy; if it looks like the clipping is going to be difficult due to complex anatomy, severe scarring, or vasospasm. The probe-holder can be stabilized and placed on the dome of the aneurysm using free-hand technique or a retractor holder. The only exposure needed, is some part of the dome. The neck of the aneurysm need not be visualized or dissected; the perforating vessels adjacent to the aneurysm need not be disturbed. This would reduce retraction and operating time, and post-operative vascular spasm. This method could also be used to implant "the web device" [10].

There is are distinct advantages of direct coiling over endovascular coiling. There is a much shorter path for the coil to travel with direct coiling compared to endovascular coiling. This theoretically reduces the risk of the procedure. Furthermore, on the long path, the catheter used for coiling can cause damage to the vessel it is traveling. The risks include dissection, perforation, or intimal tear with clot formation. In direct puncture, the course is short and there is direct passage of the coil into the aneurysm. Furthermore, in endovascular procedures, coils are pushed through the neck towards the dome, which is the weaker part of the aneurysm. This could cause aneurysm perforation [2]. With direct aneurysm coiling, coils are pushed away from the dome. This could lessen the chance of aneurysm rupture during the procedure. However, there still exists the risk for pushing the coil into the neck. In this study, none of the coils entered the neck. This could be because the coil diameter was larger than the neck. This risk would cease to exist if, "the web device" is used.

\section{Conclusion}

This feasibility study was done in an in vitro model to determine the ease and safety of doing stereotactic direct coiling of intracranial aneurysms. The study shows that needle puncture and coiling of the aneurysm through the needle can be done with ease and without any significant fluid leak from the puncture site. It also shows that if the coil diameter is larger than the neck of the aneurysm, the coil will not enter the neck. The study also shows that this method can be done using freehand technique. Furthermore, it shows that the probe holder for the needle can also be used as an aneurysm stabilizer and as a tamponade.

\section{Acknowledgements \\ None}

\section{Authors' contributions}

AP is the main author who did all the studies and wrote the paper. DKP did data analysis and statistical studies. SK was the technician who helped with the study. AC provided help in planning the study. MJ is a student who participated in all the experiments. All authors have read and approved the manuscript.

\section{Funding}

There was no external funding for this paper.

\section{Availability of data and materials}

All data generated or analyzed during this study are included in this published article [and its supplementary information files].

\section{Declarations}

Ethics approval and consent to participate Not applicable

\section{Consent for publication}

Not applicable

\section{Competing interests}

All authors certify that they have no affiliations with or involvement in any organization or entity with any financial interest (such as honoraria; educational grants; participation in speakers' bureaus; membership, employment, consultancies, stock ownership, or other equity interest; and expert testimony or patent-licensing arrangements), or non-financial interest (such as personal or professional relationships, affiliations, knowledge, or beliefs) in the subject matter or materials discussed in this manuscript.

\section{Author details}

'Department of Surgery, Creighton University School of Medicine, 7710 Mercy Road, Suite 501, Omaha, NE 68124, USA. ${ }^{2}$ Spine-Frontier, Inc., Malden, MA 02148, USA. ${ }^{3}$ Department of Neurosurgery, St. John's Medical Academy, Bangalore, India.

Received: 15 September 2020 Accepted: 7 April 2021

Published online: 28 October 2021

\section{References}

1. Etminan N, Chang H, Hackenberg K, de Rooij N, Vergouwen M, Rinkel G, et al. Worldwide incidence of aneurysmal subarachnoid hemorrhage according to region, time period, blood pressure, and smoking prevalence in the population. A systematic review and meta-analysis. JAMA Neurol. 2019;76(5):588-97.

2. van Rooij WJ, Sluzewski M, Beute GN, Nijssen PC. Procedural complications of coiling of ruptured intracranial aneurysms: incidence and risk factors in a consecutive series of 681 patients. AJNR Am J Neuroradiol. 2006;27:1498501.

3. Lindgren A, Vergouwen MD, van der Schaaf I, Algra A, Wermer M, Clarke MJ, et al. Endovascular coiling versus neurosurgical clipping for people with aneurysmal subarachnoid haemorrhage. Cochrane Database Syst Rev. 2018; 8:CD003085.

4. Dik AK, Vanlangenhove P, Dhondt E, Defreyne L. Direct puncture approach for embolization of visceral aneurysms. J Vasc Interv Radiol. 2015;26(Issue 2, Supplement):S155-6. 
5. Berkmen T, Troffkin N, Wakhloo AK. Direct percutaneous puncture of a cervical internal carotid artery aneurysm for coil placement after previous incomplete stent-assisted endovascular treatment. Am J Neuroradiol. 2003; 24(6):1230-3.

6. Smith RW, Alksne J. Stereotaxic thrombosis of inaccessible intracranial aneurysms. J Neurosurg. 1977;1977(47):833-9.

7. Patil A, Nagara M. Recoiling suture and methylmethacrylate in aneurysm thrombosis. Preliminary report. Acta Neurochir. 1984;72(1-2):73-8.

8. Patil A, Yamanashi W, Valentine J, Hill D, Woosley R, Filip O. Electromagnetic field focusing (EFF) probe in aneurysm thrombosis. Acta Neurochir. 1986;81: 68-71.

9. Meyer CH, Kaymak H, Liu Z, Saxena S, Rodrigues EB. Geometry, penetration force and cutting profile of different 23-gauge trochars systems for par plana vitrectomy. Retina. 2014;0:1-10.

10. Armoiry X, Turjman F, Hartmann DJ, Sivan-Hoffmann R, Riva R, Labeyrie PE, et al. Endovascular treatment of intracranial aneurysms with the WEB device: a systematic review of clinical outcomes. AJNR Am J Neuroradiol. 2016;37(5):868-72.

\section{Publisher's Note}

Springer Nature remains neutral with regard to jurisdictional claims in published maps and institutional affiliations.

\section{Submit your manuscript to a SpringerOpen ${ }^{\circ}$ journal and benefit from:}

- Convenient online submission

- Rigorous peer review

- Open access: articles freely available online

- High visibility within the field

- Retaining the copyright to your article

Submit your next manuscript at $\boldsymbol{\nabla}$ springeropen.com 